các nghiên cứu khác. Đào Trung Nguyên [5] cho thấy đối tượng có kiến thức đạt về các phương pháp tự khám vú thì có tỷ lệ thực hành các phương pháp phát hiện sớm UTV cao hơn so với nhóm không nhận được nguồn thông tin về UTV, có kiến thức không đạt. Rõ ràng, có nhận được nguồn thông tin và có kiến thức đạt sẽ giúp họ biết được cách thực hành như thế nào là đúng, khám với tần suất như thế nào là phù hợp cũng như thời điểm, thời gian định kỳ cần đi khám, sàng lọc phát hiện sớm những bất thường sớm để có thể điều trị kịp thời. Kết quả này cũng tương đồng với nghiên cứu của Tam Trương Donnelly cho rằng có nhận thức cao hơn dẫn đến thực hành phát hiên sớm UTV tốt hơn ở những phụ nữ được nghiên cứu tại Ả rập [8]. Hay nghiên cứu của tác giả Bùi Thị Thảo tại Hà Nội cho thấy nhóm có kiến thức chưa đạt về tự khám vú thì có điểm thực hành chưa đạt cao gấp 4,3 lần nhóm có kiến thức đạt. Qua đó chúng ta có thể thấy, vai trò quan trọng của việc cung cấp nguồn thông tin về phòng và phát hiện sớm UTV. Để có thể tăng tỷ lệ thực hành phòng và phát hiện sớm UTV ở phụ nữ thì cần phải tăng tỷ lệ có kiến thức đạt qua các hoạt động, chương trình tuyên truyền, hướng dẫn và cung cấp thông tin.

\section{KẾT LUÂ̂N}

Yễu tố liên quan kiến thức về phòng và phát hiện sớm UTV ở phụ nữ 18-60 tuổi: sống thành thị, học vấn > THCS và có tìm hiểu thông tin về UTV có kiến thức tốt hơn nhóm còn lại lần lượt $1,944(1,015-3,722) ; 2,856 \quad(1,169-6,979)$ và $3,264(1,728-6,163)$ với $p<0,05$. Về thực hành, thực hành tốt cao hơn ở nhóm tiền sử gia đình có UTV, chủ động tìm hiểu thông tin về UTV và kiến thức tốt lần lượt 4,106 (1,404-12,01); 2,763 $(1,298-5,882)$ và $2,089(1,01-4,32)$ với $p<0,05$.

\section{TÀI LIÊU THAM KHẢO}

1. Nguyễn Hữu Châu (2015), "Nghiên cứu thực trạng kiến thức, thái độ, thực hành về bệnh ung thư vú ở phụ nữ 20 - 60 tuổi trên đia bàn tỉnh Khánh Hòa", Tạp chí Ung thư học Việt Nam, số 5/2015, tr.22-25.

2. Bùi Thị Duyên (2018). Kiến thức, thái độ và thưc hành phát hiên sớm ung thư vú và một số yếu tố liên quan của phụ nữ tữ 20 - 49 tuổi tại xã Cẩm Giang, Huyện Cẩm Thủy, Thanh Hóa, Luận văn thăc sỹ Y tế công cộng, Trường Đại hợ Y Y HN.

3. Nguyễn Thị Quế Lâm (2017), Tìm hiểu một số yêu tố liên quan đến kiến thức, thái độ và thực hành về phòng chống bệnh ung thư vú ở phụ nữ thị xã Ninh Hòa, tỉnh K̉hánh Hòa, Đề tài cơ sở Trung tâm Truyền thông GDSK Khánh Hòa

4. Đào Trung Nguyên (2017), Kiến thức, thực hành về phòng và phát hiện sớm ung thư vú của phư nữ ở công ty cổ phần may 10 và một số yếu tố liên quan, Luận văn tốt nghiệp trường địa học $Y$ Hà Nội.

5. Phạm Cẩm Phương (2017), "Đánh giá kết quả tư vấn khám sàng lọc và phát hiên sớm ung thư vú ở nữ giới tại thành phô Hà Nội và các tỉnh lân cận", Tạp chí y học Việt Nam, Tập 1, tr. 41-45.

6. Đố Quốc Tiệp, Mái Xuân Sự, Phan Tiến Hoàng và cô̂ng sứ (2015). Nghiên cứu kiến thức cửa người dân về phòng chống bệnh ung thư tại Quảng Bình. Tạp chí Ung thư học Việt Nam, số 5/2015, tr.41-44.

7. Deniz S, Kurt B, Oğuzöncül AF, Nazlıcan E, Akbaba M, Nayir T (2017). Knowledge, attitudes and behaviours of women regarding breast and cervical cancer in Malatya, Turkey. Plos One, Vol 12 (11), pp.1-9.

8. Donnelly TT, Khater AH, Al-Bader SB, Al Kuwari MG, Malik M, Al-Meer N, Singh R, Fung $T$ (2014). Factors that influence awareness of breast cancer screening among Arab women in Qatar: results from a cross sectional survey. Asian Pac J Cancer Prev, Vol 15 (23), pp.10157-10164.

9. WHO (2018). New Global Cancer Data: GLOBOCAN 2018.

\title{
ĐÁNH GIÁ KẾT QUẢ ĐÎ̀̂U TRI VẾT LOÉT LÂU LIỀN CHI DƯớI Ở NGƯỜI LỚN TUỔI
}

\section{TÓM TẮT}

Mục tiêu: Đánh giá kết quả điều trị vết loét lâu liền chi dưới ở người lớn bằng tại Bệnh viện Thống

*Bênh viện Thống Nhất, TP Hồ Chí Minh

Chịu trách nhiệm chính: Võ Thành Toàn

Email: vothanhtoan1990@yahoo.com

Ngày nhận bài: 5.01.2021

Ngày phản biện khoa học: 25.2.2021

Ngày duyệt bài: 9.3.2021

\section{Võ Thành Toàn*, Nguyễn Bảo Lục*}

Nhất. Đối tượng và phương pháp: 40 bệnh nhân độ tuổi từ 60 trở lên, có các vết loét lâu liền chi dưới do nhiều nguyên nhân được điều trị tại khoa Chấn thương Chỉnh hình, bệnh viện Thống Nhất từ 1/2018 đến 1/2019. Kết quả: Có 20 ca ghép da với tỉ lệ sống 75 - 100\%; 4 ca được chuyển vạt hiển che phư với 3 vạt sống hoàn toàn; 8 ca chuyển vạt da cân cẳng chân cuống ngoại vi sống hoàn toàn. Chuyển vạt cân mõ với 4 ca vết thương chậm liền. Ngoài ra có 4 ca chuyển vạt cơ sinh đôi thành công. Kêt luận: Vết loét chi dưới có nguyên nhân đa dạng hay gặp nhất là ở 
cổ chân và bàn chân; diễn tiến trong thời gian dài, thường lộ gân, xương và bệnh nhân kèm theo nặng. Điều trị các vết loét lâu liền chi dưới phải can thiệp ngoại khoa. Điều trị bệnh toàn thân sau đó ghép da, chuyển vạt da góp phần giúp vết loét phuc hồi nhanh hơn.

Tư khoá: Vết loét lâu lành chi dưới.

\section{SUMMARY \\ EVALUATION RESULTS TREATMENT OF LONG-TERM ULCERS OFLOWER EXTREMITIES IN ELDER}

Objective: Evaluation results treatment of lonaterm lower extremities ulcer in elder at Thong Nhat hospital. Materials and methods: 40patients aged 60 and over with long-term ulcers of lower extremities due to many causes are treated at the Department of Trauma and Orthopedics from January 2018 to January 2019. Results: There are 20 cases of skin grafting with the survival rate of $75-100 \%$, 4 cases being transformed to cover flap with 3 completely successful flaps; 8 cases of skin flap transfer with lower legs, completely successful peripheral stem flaps. Transfer fat flap with 4 cases of slow healing. In addition, there are 4 successful twins flap transfers. Conclusion: Lower limb ulcers have a variety of causes, most commonly in the ankles and feet; Proqressing over a lonq period of time, often revealing tendons, bones and patients with severe comorbidity. Treatment of ulcers for lonq-term healing of lower extremities requires surqical intervention. Systemic treatment followed by skin qraftinq; skin flap transfer contributes to faster recovery of ulcers.

Key words: long-term ulcers of lower extremities.

\section{I. ĐĂT VẤN ĐỀ}

Vết loét vùng chi dưới là thương tổn hay gặp do nhiều nguyên nhân như: tai nạn giao thông, tai nạn sinh hoạt, di chứng vết thương, biến chứng của nhiều bệnh lý.

Kích thước các vết thương, vết loét này thường không quá lớn. Nhưng do đặc điểm giải phẫu cũng như chức năng của vùng này nên thường gặp khó khăn trong điều trị. Các tổn thương trên thường gây viêm xương, khớp, lộ gân... Đặc biệt ở người lớn tuổi, thường kèm theo nhiều bệnh lý như: đái tháo đường, viêm, tắc mạch máu và các rối loạn chuyển hóa khác nên việc điều trị càng khó khăn hơn.

Về điều trị cơ bản là phải can thiệp bằng ngoại khoa như cắt lọc, thay băng. Với các vết loét có kích thước lớn hơn hoặc nhỏ nhưng sâu, lộ gân, xương, khớp... ngoài cắt lọc ổ viêm còn phải tiến hành các can thiệp khác như ghép da, chuyển vat da.

Tại khoa ngoại Chấn thương Chỉnh hình, Bệnh viện Thống Nhất chúng tôi gặp khá nhiều bệnh nhân cao tuổi bị tổn thương này. Do đó chúng tôi nghiên cứu đề tài nhằm mục đích: Nghiên cứu đặc điểm tôn thương của các vêt loét lâu liền chi dưới ở người lớn tuổi và đánh giá kêt quả điều trị tổn thương này.

\section{II. ĐỐI TƯợNG VÀ PHƯƠNG PHÁP NGHIÊN CỨU}

Nghiên cứu tiến cứu trên 40 bênh nhân đô tuổi từ 60 trở lên, có các vết loét lâu liền chi dưới do nhiêu nguyên nhân được điều trị tại khoa ngoại Chấn thương Chỉnh hình, bệnh viện Thống Nhất, từ $1 / 2018$ đến $1 / 2019$

\section{KẾT QUẢ NGHIÊN CỨU VÀ BÀN LUÂ̂N}

3.1. Phân loại theo tuổi, giới: Trong 40 bệnh nhân nhóm chúng tôi nghiên cứu. Người lớn tuổi tính từ 60 trở lên được chia làm 3 nhóm và phân loại theo giới tính.

Bảng 3.1. Phânloại theo tuổi và giới $(n=40)$

\begin{tabular}{|c|c|c|c|c|}
\hline $\begin{array}{c}\text { Độ } \\
\text { tuổi }\end{array}$ & $\begin{array}{c}\mathbf{6 0 - 7 0} \\
\text { tuổi }\end{array}$ & $\begin{array}{c}\mathbf{7 1 - 8 0} \\
\text { tuổi }\end{array}$ & $\begin{array}{c}\text { Trên 80 } \\
\text { tuối }\end{array}$ & Tổng \\
\hline Nam & 9 & 11 & 4 & 24 \\
\hline Nữ & 3 & 7 & 6 & 16 \\
\hline Tống & 12 & 18 & 10 & 40 \\
\hline
\end{tabular}

Phân loai trên 40 bênh nhân: Nam 24 BN; Nữ

16 BN. Tuổi cao nhất: 94. Tuổi ít nhất: 60 .

3.2. Nguyên nhân tổn thương:

Bảng 3.2. Nguyên nhân tổn thương thường gặp $(n=40)$

\begin{tabular}{|c|c|c|}
\hline Nguyên nhân & $\begin{array}{c}\text { Số bệnh } \\
\text { nhẩn }\end{array}$ & Tỷ lệ \\
\hline Di chứng vết thương hỏa khí & 8 & $20 \%$ \\
\hline Do tai nạn giao thông & 10 & $25 \%$ \\
\hline Do tai nạn sinh hoạt & 12 & $30 \%$ \\
\hline Biến chứng đái tháo đường & 10 & $25 \%$ \\
\hline
\end{tabular}

3.3. Vị trí, kích thước và tính chất thương tổn:

Bảng 3.3. Vị trí thương tổn $(n=40)$

\begin{tabular}{|c|c|c|}
\hline Vị trí thương tổn & $\begin{array}{c}\text { Số bệ̂nh } \\
\text { nhẩn }\end{array}$ & Tỷ lệ \\
\hline $1 / 3$ trên cắng chân & 2 & $5 \%$ \\
\hline $1 / 3$ giữa cắng chân & 4 & $10 \%$ \\
\hline $1 / 3$ dưới cằng chân & 6 & $15 \%$ \\
\hline Cố chân và gót chân & 16 & $40 \%$ \\
\hline Bàn chân & 12 & $30 \%$ \\
\hline
\end{tabular}

Vết thương vết loét lâu liền xảy ra chủ yếu ở vùng cổ chân, gót chân và bàn chân với $28 / 40$ $\mathrm{BN}$ chiếm $70 \%$. Đây là là vùng rất ít cớ, lớp mõ dưới da mỏng, sát xương, khớp nên rất khó liền. Đây cũng là vùng dễ va chạm, dễ tổn thương. Các phương pháp kinh điển (ghép da tự thân) thường ít phù hợp do rất khó tạo được nền nhận tốt. Ngay cả khi mảnh da ghép có bám được thì nguy cơ trợt, loét tái phát là rất dễ xảy ra.

\section{Bảng 3.4. Kích thước thương tổn}




\begin{tabular}{|c|c|c|}
\hline $\begin{array}{c}\text { Kích thước } \\
\text { thương tổn }\end{array}$ & $\begin{array}{c}\text { Số bệnh } \\
\text { nhấn }\end{array}$ & Tỷ lệ \\
\hline Dưới $20 \mathrm{~cm}$ & 12 & $30 \%$ \\
\hline Từ $20-40 \mathrm{~cm}$ & 18 & $45 \%$ \\
\hline Trên $40 \mathrm{~cm}$ & 10 & $25 \%$ \\
\hline
\end{tabular}

Đa số tốn thương có kích thước vừa và nhỏ với 30/40 BN chiếm 75\% tổng số ca nghiên cứu.

Bảng 3.5. Tính chất thương tổn $(n=40)$

\begin{tabular}{|c|c|c|}
\hline Tính chất thương tổn & $\begin{array}{c}\text { Số bệnh } \\
\text { nhẩn }\end{array}$ & $\begin{array}{c}\text { Tỷ } \\
\text { lệ }\end{array}$ \\
\hline $\begin{array}{c}\text { Tốn thương phần mềm } \\
\text { đơn thuần }\end{array}$ & 18 & $45 \%$ \\
\hline $\begin{array}{c}\text { Tốn thương phần mềm } \\
\text { kèm tổn thương gân }\end{array}$ & 18 & $45 \%$ \\
\hline $\begin{array}{c}\text { Tốn thương phần mềm } \\
\text { kèm viêm xương }\end{array}$ & 4 & $10 \%$ \\
\hline
\end{tabular}

Có $8 \mathrm{BN}$ vết thương mất da vùng gót, gần điểm bám tận của gân Achille. 4 BN hoại tử da mu chân do biến chứng tắc mạch ngoại vi do biến chứng đái tháo đường. Hai bệnh nhân bị lộ gân duỗi ngón chân phải cắt bỏ hoại tử, thay băng chờ tổ chức hạt mọc và ghép da.

3.4. Thời gian: $(n=40)$

Bảng 3.6. Thời gian tồn tại thương tổn

\begin{tabular}{|c|c|c|}
\hline Thời gian & Số bệnh nhân & Tỷ lệ \\
\hline Dưới 1 tháng & 4 & $10 \%$ \\
\hline Từ 1 tháng đến 1 năm & 20 & $50 \%$ \\
\hline Trên 1 năm & 16 & $40 \%$ \\
\hline
\end{tabular}

Dưới 1 tháng: bệnh nhân chủ yếu bị vết thương do tai nạn giao thông có mất da vùng gót và bàn chân. Từ 1 tháng đến 1 năm có20 trường hợp với nguyên nhân thương tổn đa dạng hơn. Trên 1 năm có 16 bênh nhân; thời gian dài nhất là trên 20 năm chủ yếu là nhóm bệnh nhân do di chứng vết thương hỏa khí gây sẹo xấu vùng cẳng chân, gân Achille, vết thương thường có nhiều đợt tái phát.Đặc điểm chung của các bệnh nhân là đều trải qua một thời gian dài vết thương bị nhiễm khuẩn, đã được điều trị nhiều lần bằng phẫu thuật, kháng sinh.

3.5. Các bệnh lý kèm theo:

Bảng 3.5. Các bệnh lý đí kèm $(n=40)$

\begin{tabular}{|c|c|}
\hline Bệnhh lý đi kèm & Số bệnh nhân \\
\hline Tăng huyết áp & $30 / 40$ \\
\hline Đái tháo đường & $20 / 40$ \\
\hline Suy van tĩnh mạch & $35 / 40$ \\
\hline Bệnh mạch vành & $16 / 40$ \\
\hline
\end{tabular}

Đặc điểm chung của các BN có vết loét lâu liền chi dướicao tuổi là nhiều bệnh nền. Do đó khi điều trị cần phối hợp các chuyên khoa nhằm đưa các chỉ số về gần giới hạn bình thường như: đường máu, huyết áp... và duy trì suốt trong quá trình điều trị.
3.6. Phương pháp điêu trị đã sử dụng:

Tất cả các vết thương đều được cắt lọc, làm sach sau đó tiến hành che phủ da thì 2 :

Bảng 3.6. Các phương pháp điều trị $(n=40)$

\begin{tabular}{|c|c|}
\hline Phương pháp đîêu trị & Số bệnh nhân \\
\hline Ghép da mỏng tự thân & 20 \\
\hline $\begin{array}{c}\text { Chuyến vạt da cân có cuống } \\
\text { mạch nuôi }\end{array}$ & 8 \\
\hline Chuyến vạt da cân cằng chân & 3 \\
\hline Chuyến vạt cân mỡ & 3 \\
\hline Vạt cớ sinh đôi trong & 4 \\
\hline Tự liền & 2 \\
\hline
\end{tabular}

Chỉ định sử dụng phương pháp điều trị căn cứ chủ yếu vào tình trạng thương tổn, kích thước, vị trí tổn thương và nơi lấy chất liệu che phủ. Ngoài ra, còn căn cứ vào độ tuổi của bệnh nhân. Các bệnh nhân trên 80 tuổi chủ yếu sử dụng phương pháp kinh điển (ghép da tự thân).

3.7.Kết quả điêu trị. Trong nghiên cứu chúng tôi gồm có $20 \mathrm{BN}$ được ghép da mỏng tự thân với tî lệ sống 75 - 100\%. Các bệnh nhân này có các vết thương do biến chứng của đái tháo đường gây hoại tử da, lộ gân duỗi bàn chân. Đã được cắt lọc hoại tử, săn sóc vết thương. Sau khi tổ chức hạt phát triển ổn định thì tiến hành ghép da mỏng tự thân. Nhửng trường hợp này có chỉ định sử dụng vạt có cuống nhưng không thực hiện được do điều kiện toàn thân (tuổi cao) và tại chố (bệnh lý mạch máu ngoại vi) không cho phép lấy vạt.

Bệnh cạnh đó 4 BN được chuyển vạt hiển che phủ tổn khuyết với 3 vạt sống hoàn toàn; 1 bị hoại tử một phần nhưng không phải can thiệp bổ sung, trường hợp này là một bệnh nhân bị vết thương mất da gót, lộ gân Achille có tiền sử bệnh mạch vành ba nhánh, suy van tĩnh mạch chi dưới. Có 8 BN chuyển vạt da cân cẳng chân cuống ngoại vi sống hoàn toàn. Bệnh nhân bị loét lâu liền vùng mắt cá ngoài do biến chứng đái tháo đường, tăng huyết áp. Vạt da cân sống hoàn toàn. Vết mổ liền kỳ đầu. Kiểm tra sau 6 tháng kết quả tốt.

Trường hợp 4 BN được chuyển vạt cân mõ (che phủ gân Achille): vết thương chậm liền. Tự liền sau 2 tháng. Bệnh nhân bị di chứng vết thương hỏa khí (trên 20 năm) lộ và viêm gân gót. Ngoài ra có $4 \mathrm{BN}$ chuyển vạt cơ sinh đôi trong: vạt sống, nhưng rò kéo dài. Nguyên nhân do viêm xương chây mãn tính nhiều năm.

\section{KẾT LUÂ̂N}

Đặc điểm các vết loét lâu liền chi dưới: kích thước chủ yếu vừa và nhỏ với nguyên nhân đa 
dang. Vi trí hay găp nhất là ở cổ chân và bàn chân. Các vết loét diễn ra trong thời gian dài, đều ở giai đoạn mạn tính và thườnglộ gân, xương. Đa số bệnh nhân kèm theo nhiều bệnh lý toàn thân như: tăng huyết áp, đái tháo đường... Kết quả điều trị các vết loét lâu liền chi dưới cho thây can thiệp ngoại khoa là chỉ định chính: cắt lọc, thay băng, dùng kháng sinh, bất động. Bên canh đó việc điều trị bệnh toàn thân góp phần rất quan trọng.

\section{TÀI LIÊU THAM KHẢO}

1. Masquelet AC, RomanaMC, Wolf G(1992), "Skin island flaps supplied by the vascular axis of the sensitive superficial nerves: anatomic study and clinical experience in the leg". Plast. Reconstr. Surg; 89: 1115-20.

2. Touam $\mathbf{C}$, Roustoucher $\mathbf{P}$, Bhatia $\mathbf{A}$, Oberlin $\mathbf{C}$ (2001), "Comparative study of two series of distally based fasiocutaneous flaps for coverage of the lower one-fourth of the leg, ankle, and the foot".Plast. Reconstr. Surg; Feb; 107 (2): $383-92$.

3. Lê Văn Đoàn, Nguyễn Viết Tiên, Lưu Hồng Hải và CS (2006), "Kết quả sử dụng các vat cơ có cuống mach nuôi trong điều tri tốn khuyết vùng gối, cằng chân, cổ chân và bàn chân". Tạp chí Y dược lâm sàng 108- Hà Nôii; 51-56.

4. Tăng Hà Nam Anh, T. Bauer, F. Rimarnex, A Lortat-Jacob (2006); "Che phủ khuyết hổng phân mềm vùng cẳng chân và cổ chân bằng vat da cân cẳng chân cuống mạch xa." Tạp chí Ỳ dược lâm sàng 108- Hà Nội 2006: 39 -45.

\section{ĐốI CHIẾU HİNH ẢNH SIÊU ÂM VỚI SOI TỬ CUNG Ở BÊNH NHÂN ĐẾN KHÁM TẠI BỆNH VIỆN ĐẠI HỌC Y THÁI Bİ̀NH}

\section{TÓM TẮT}

Mục tiêu: Đối chiếu hình ảnh siêu âm với kết quả soi buồng tử cung. Đối tượng và phương pháp nghiên cứu: Nghiên cứu mổ tả cắt ngang, trên 300 bềnh nhân. Kết quả: Trong chẩn đoán quá sản nôi mạc tử cung, soi buồng tử cung có độ nhạy là $71 \%$, cao hơn nhiếu so với siêu âm (13\%). Trong chẩn đoán polype buồng tử cung, soi buồng tử cung có độ nhạy $(100 \%)$ cao hơn siêu âm $(81 \%)$. Siêu âm và soi buồng tử cung đều có độ nhạy không cao trong chẩn đoán u xơ tử cung, lần lướt là $67 \%$ và $56 \%$. âm

Từ khoá: Buồng tử cung, soi buồng tử cung, siêu

\section{SUMMARY \\ COMPARE THE ULTRASOUND WITH THE UTERINE EXAMINATION OF PATIENTS COMING TO THAI BINH MEDICAL UNIVERSITY HOSPITAL}

Objective: Reconcile ultrasound images with hysteroscopy. Subjects and research methods: Cross-sectional descriptive study, over 300 patients. Results: In diagnosing endometrial hyperplasia, hysteroscopy is $71 \%$ sensitive, much higher than ultrasound (13\%). In the diagnosis of uterine polyps, hysteroscopy is more sensitive $(100 \%)$ than ultrasound (81\%). Ultrasound and hysteroscopy were not highly sensitive in the diagnosis of uterine fibroids, respectively $67 \%$ and $56 \%$.

Keywords: Uterine chamber, hysteroscopy, ultrasound

*Trường Đai hoc Y Dước Thái Bình

Chịu trách nhiếm chính: Nquyễn Ngọc Trung

Email: trungnn@tbump.edu.vn

Ngày nhân bài: 4.01.2021

Ngày phản biên khoa hoc: 26.2.2021

Ngày duyệt bài: 8.3.2021

\section{I. ĐĂT VẤN ĐỀ}

Các bất thường buồng tử cung như: $u$ xơ, polype, u xơ dưới niêm mạc, vách ngăn, dính buồng, quá sản niêm mạc... gây ra rong kinh, rong huyết, ra máu bất thường đặc biệt gây vô sinh, sảy thai liên tiếp, thiếu máu do ra máu kéo dài. Các bất thường này ảnh hưởng rất nhiêu đến kinh tế và cuộc sống của người bệnh. Việc phát hiện, chẩn đoán sớm các bệnh lý trên giúp thây thuốc lâm sàng ra quyết định kịp thời điều trị tích cực nhằm hạn chế tối đa các biến chứng, đảm bảo chất lượng cuộc sống cho bệnh nhân.

Ngày nay, để chẩn đoán các bất thường trong buồng tử cung, ngoài biểu hiện của các triệu chứng lâm sàng, đã có một số phương pháp thăm dò hỗ trợ có tính chất quyết định như: siêu âm, chụp buồng tử cung có bơm thuốc cản quang [3], [4], [5].

Siêu âm tuy đơn giản, không độc hại nhưng độ nhạy và độ đặc hiệu không cao. Hiện nay, biện pháp siêu âm bơm nước vào buồng tử cung cho phép chẩn đoán u xơ tử cung, polype buồng tử cung chính xác hơn.

Soi buồng tử cung là một phương pháp rất có giá trị hiện nay trong việc chẩn đoán các bệnh lý tại buồng tử cung. Soi buồng tử cung cho phép quan sát được toàn bộ niêm mạc tử cung, giúp chẩn đoán polype buồng tử cung, u xơ dưới niêm mạc tử cung, dị dạng buồng tử cung, vách ngăn buồng tử cung, ung thư niêm mạc tử cung, teo và quá sản niêm mạc tử cung. Đặc biệt là qua soi buồng tử cung chúng ta có thể sinh thiết 